\title{
Assessing and Responding in Real Time to Online Anti-vaccine Sentiment during a Flu Pandemic
}

Neil Seeman, Alton Ing and Carlos Rizo

\begin{abstract}
The perceived safety of vaccination is an important explanatory factor for vaccine uptake and, consequently, for rates of illness and death. The objectives of this study were (1) to evaluate Canadian attitudes around the safety of the H1N1 vaccine during the fall 2009 influenza pandemic and (2) to consider how public health communications can leverage the Internet to counteract, in real time, anti-vaccine sentiment.

We surveyed a random sample of 175,257 Canadian web users from October 27 to November 19, 2009, about their perceptions of the safety of the HINI vaccine. In an independent analysis, we also assessed the popularity of online flu vaccine-related information using a tool developed for this purpose. A total of 27,382 unique online participants answered the survey (15.6\% response rate). Of the respondents, $23.4 \%$ considered the vaccine safe, $41.4 \%$ thought it was unsafe and $35.2 \%$ reported ambivalence over its safety. Websites and blog posts with anti-vaccine sentiment remained popular during the course of the pandemic.

Current public health communication and education strategies about the flu vaccine can be complemented by web analytics that identify, track and neutralize anti-vaccine sentiment on the Internet, thus increasing perceived vaccine safety. Counter-marketing strategies can be transparent and collaborative, engaging online "influencers" who spread misinformation.
\end{abstract}

$\mathrm{P}$ rior to the 2009 influenza A (H1N1) pandemic, public health experts recognized that communities throughout the globe were deficient in pandemic planning (Mareinniss et al. 2009) and could benefit from strategies to increase vaccination rates. In any epidemic, high vaccination uptake is essential in order to limit transmission, protect groups at high risk, reduce the number of severe outcomes and prevent an overload of health services use. Inadequate information about the protective effects of a demonstrably safe flu vaccine reduces immunization rates, contributing to a more rapid spread and wider distribution of an epidemic. Healthcare workers are at particular risk, and, accordingly, in some jurisdictions such as Ontario, it is a hospital board-level responsibility to ensure rapid-response emergency preparedness plans are in place to protect the safety of hospital workers in the event of an infectious outbreak (Seeman et al. 2008).

Systematic reviews show that vaccines prevent infection, complication and death, especially when provided to groups at high risk (Jefferson et al. 2008). Why, then, do many people choose not to be vaccinated? Reasons include a lack of familiarity with the epidemiological facts, a lack of support or notification from the healthcare system and unfounded fears about vaccine safety (Baeyens 2010; Maurer et al. 2010). Common fears are that a new vaccine has been rushed to production with insufficient prior research, that it has not been adequately tested and that long-term studies are needed (Seale et al. 2010). General 
anti-vaccination sentiment has been growing worldwide due to the well-publicized but unsubstantiated link between flu immunization and autism; between hepatitis $B$ vaccination and multiple sclerosis in France; and between convulsions and sudden death and human papillomavirus immunization in Austria, Germany and Spain (Alvarez-Pasquin et al. 2009).

Efforts to offset the arguments of the anti-vaccine movement, to calm public fears and to provide accurate information require sustained, effective public health communication. Concerns about safety and side effects need to be addressed; as well, transparency is required about the vaccine development process. Was this successfully accomplished in Canada? A poll conducted between October 1 and 5, 2009, by Harris-Decima revealed that only a third of Canadians intended to get vaccinated, $11 \%$ described themselves as very concerned about $\mathrm{H} 1 \mathrm{~N} 1$ and $25 \%$ reported being somewhat concerned (Harris-Decima 2009). The federal health minister noted that the biggest challenge to preventing the spread of the virus was communicating the need for vaccination. Health Canada's information about vaccine safety was broadly disseminated on posters, on buses and subways, in multi-language newspapers and on social media such as Facebook. The information was posted on government and hospital websites across Canada, and Health Canada's website was prominently hyper-linked via mainstream Canadian media news sites. This seemed like a logical communications strategy given that the news media have been a leading source of public health information (Gollust and Lantz 2009).

The challenge with social risk communication in the age of the Internet is the increasing fragmentation of media (Sunstein 2007). Today, Canadians access health information not through print newspapers, radio or cable television but predominantly through the Internet. For at least five years, the first place people seek health-related information has been the web (Hesse et al. 2005). Unfortunately, some Internet sites and postings, light on facts and packed with emotionally laden anecdotes, worsen concerns regarding vaccination safety (Maurer et al. 2010; Wolfe et al. 2002).

Given the degree to which the public accesses vaccine-related information online, we wanted to track whether online postings about the $\mathrm{H} 1 \mathrm{~N} 1$ flu vaccine were undermining ongoing communications efforts by public health authorities during the fall of 2009. We also wanted to know whether anti-vaccine sentiment escalated after Health Canada's approval of the vaccine and, if so, to suggest Internet communications strategies (Rizo et al. 2005) at the national, regional and hospital levels that could assess, monitor and, ideally, counteract such sentiment.

\section{Methodology}

Two parallel, independent steps were initiated to address our objectives. In step A, we surveyed a random sample of Canadian web users from October 27 to November 19, 2009, about their perceptions of the safety of the H1NI vaccine after Health Canada approved the vaccine. In step B, we determined which vaccine safety Internet sites were most trusted by the public by deploying a dynamic "Internet robot" that informed us about (1) which uniform resource locators (URLs) regarding "myths and facts" about the H1N1 vaccine were being most widely shared and discussed among English-language Internet users and (2) which websites, blogs and links were being shared on social media sites. Both step A (the survey) and step B (the Internet robot) were independent, and the results should be interpreted as such. Both steps of our process are described below.

\section{Step A: Random Online Survey of Internet Users' Perceptions of Vaccine Safety}

For the survey of Internet users' perceptions of vaccine safety, we used the RIWI Time Trender service (http://riwi.com), which applies a patent-pending Internet intercept method that provides access to immediate respondent data based on a random sampling of Internet users. Response to the survey was randomized by accessing thousands of "nonsense" domain names (URLs) that reach hundreds of thousands of random Internet users. A nonsense domain is a URL that has no English-language meaning (e.g., www.jhwje.ca) and is not being used for commercial or other purposes. Thus, the method captures potential respondents navigating the Internet who type in nonsense domains by random accident (i.e., mistypes). The Internet intercept method is not like email spam; it is more akin to an online "random digit dialing" survey since all Internet users have a relatively equal probability of inadvertently landing on the web page where the survey is posted. Only Canadian Internet users were able to respond (geographically identified, anonymously, by their Internet protocol, or IP, address).

The survey asked, "Is the H1N1 flu vaccine safe?" Answer options were limited to "yes," "no," "don't know" and "skip." Respondents were also asked their age (under 18, 18-29, 30-49, 50-64 and over 64) and their sex. They were able to answer only once, either in English or French. The survey contained a privacy policy explaining that collected information would not identify individuals, businesses or households. Respondents were advised that information would be kept anonymous and that they had the choice not to respond.

\section{Step B: H1N1 Myth and Fact Internet Aggregator}

At the same time that we initiated the survey (October 27, 2009), we launched a software tool to count how often flu vaccine-related information websites were being shared on blogs and social media sites such as Digg, YouTube, Facebook and Twitter. We wanted to identify which websites containing information on myths and facts about the $\mathrm{H} 1 \mathrm{~N} 1$ vaccine were the most viewed, read and shared on the web. We used standardized English search strings to identify which websites were discussing 
the safety of the vaccine. Using a structured algorithm, we were able to track, on a daily basis, which of these websites were rising in popularity (i.e., were being shared with increasing frequency among web users). This is different from counting website "hits," which do not track whether the individuals visiting the site take the additional steps of creating a short form of the URL (i.e., by using popular website "shorteners" such as http://www.tinyurl. com or http://www.bit.ly) and then emailing, texting or otherwise sharing the shortened link (e.g., via Facebook or Twitter) with others. We aggregated and displayed this information in real time on a publicly accessible area called the Flu Chat Lab at http://www.myhealthinnovation.com. The dynamic aggregation of this Flu Chat Lab content is now accessible and ongoing at http://lab.innovationcell.com (Figure 1).

The computer-programmed Flu Chat Lab aggregation technique involved the following five steps:

1. 'Chatter' collection. We built a selection of relevant Englishlanguage search strings (available upon request). The goal of the search strings was to identify postings on the web that contained self-reports about the perceived truth or falsity of information concerning the H1N1 flu vaccine.

2. Data collection. All the search string queries were submitted on a daily basis into Google Search, and search results were collected in a database, with duplicate URLs removed. The first 64 top-ranked search results (for each search string) were collected daily.

3. Scoring. Each unique search result was measured for "mentions" - that is, the degree to which the URL was shared by global Internet users across the web - to establish a "chat level" in "decibels" $(\mathrm{dB})$. The aggregator tool counted the number of mentions of every search result in the database and assigned it a chat level. The chat level was calculated in units of decibels $(\mathrm{dB})$ as 20 LOG10 (9 + Mentions). This method of measuring chat level is analogous to the measurement by audio engineers of intensity, loudness and power. The logarithmic scale allowed us to visualize mentions as "audio intensity" on a linear scale.
4. Categorization of chat level. The chat level for each search result was categorized into one of four levels: high $(60 \mathrm{~dB}$ and above), medium (40-59 dB), low (20-39 dB) and none (below $20 \mathrm{~dB}$ ).

5. Daily dynamic scoring. The change in chat level (over 24 hours) was calculated in order to rank "trending" search results. On a daily basis, the chat levels for new and existing search results were updated. In this manner, we visualized the change in chat level for each search result.

\section{Results \\ Step A Findings: Daily Tracking Survey of Canadian Web Users about Perceived Vaccine Safety}

There were 27,382 unique respondents (i.e., from unique computing devices) who completed the survey, out of 175,257 separate Canadians exposed to the survey. This translated to a response rate of $15.6 \%$. The remainder of the respondents (84.4\%) chose to hit "skip" (signaling their unwillingness to complete the survey) or closed their web browsers. We verified that the target of our survey only covered Canadian IP addresses, across all provinces and territories. Each day, an average of 1,141 Canadian web users completed the survey.

Table 1 shows the relative response rate of Canadian Internet
Figure 1. Screenshot of the Flu Chat Lab

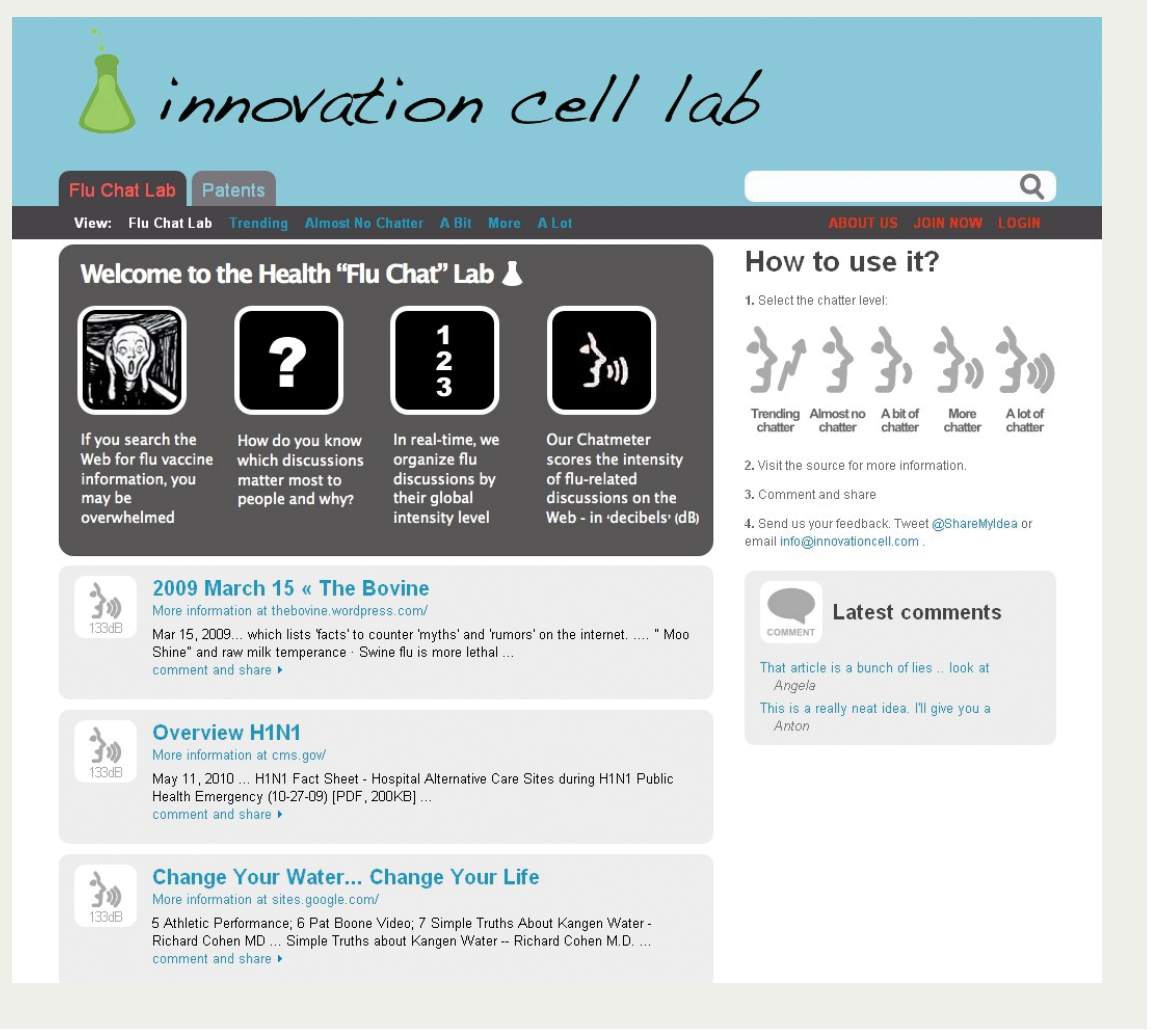


Table 1. Survey response by region compared with percentage of Canadian population

\begin{tabular}{|l|c|c|}
\hline Region & $\begin{array}{c}\text { Percentage from Each Region } \\
(\mathbf{N = 2 7 , 3 8 2})\end{array}$ & $\begin{array}{c}\text { Region Population as } \\
\text { Percentage of Population* }\end{array}$ \\
\hline Alberta & 12.3 & 10.9 \\
\hline British Columbia & 12.0 & 13.2 \\
\hline Manitoba & 3.4 & 3.6 \\
\hline New Brunswick & 2.0 & 2.2 \\
\hline Newfoundland and Labrador & 1.2 & 1.5 \\
\hline Nova Scotia & 3.4 & 2.7 \\
\hline Northwest Territories & 0.1 & 0.1 \\
\hline Nunavut & 0.1 & 0.1 \\
\hline Ontario & 41.2 & 38.7 \\
\hline Prince Edward Island & 0.5 & 0.4 \\
\hline Ouebec & 20.4 & 23.2 \\
\hline Saskatchewan & 3.2 & 3.1 \\
\hline Yukon & 0.1 & 0.1 \\
\hline
\end{tabular}

*Source: Statistics Canada (2009a).

vaccine safe, while $41.4 \%$ thought it was unsafe and $35.2 \%$ reported ambivalence over its safety. Over the 24 days surveyed, the percentage of those who said the vaccine was not safe peaked at $45.3 \%$ (on November 18, 2009). The general trend line for those who felt the vaccine was safe stayed relatively static, with a low of $21.0 \%$ (on November 17) and a high of $28.4 \%$ (on October 29), two days after Health Canada had approved the $\mathrm{H} 1 \mathrm{~N} 1$ vaccine and public health communications efforts were most visible in online and print media.

\section{Step B Findings: Aggregating Perceived}

Table 2. Survey response by sex compared to percentage of Internet users

\begin{tabular}{|l|c|c|}
\hline Sex & $\begin{array}{c}\text { Response Rate (\%) } \\
(\mathbf{N = 2 7 , 3 8 2 )}\end{array}$ & $\begin{array}{c}\text { Sex as Percentage of } \\
\text { Canadian Internet Users* }\end{array}$ \\
\hline Male & 38.8 & 50.2 \\
\hline Female & 61.2 & 49.8 \\
\hline
\end{tabular}

${ }^{*}$ Source: comScore Networks Inc. (2008).

users to the survey, comparing the response rate in each jurisdiction to its proportion in the national population. Table 1 shows responses by region compared with the percentage of the Canadian population, and Table 2 shows responses by sex compared with the Canadian population. Table 3 shows the survey responses by age compared with the relative frequency of Internet use by age group (from the most comparable data source available).

Our survey findings, illustrated in Figure 2, show that an average of $23.4 \%$ of Canadians surveyed considered the safety by chat level is described in Table 4. Appendix 1 identifies the top 20 search results discussing the safety of the vaccine.

Twelve of the 20 URLs (60\%) in Appendix 1 (http://www. longwoods.com/content/21923) contain anti-vaccine sentiment (numbers 1, 2, 3, 5, 7, 9, 10, 14, 15, 16, 17 and 19). Three of 20 (15\%) are government sources (numbers 8, 12 and 20). Our methodology indicated that each of these 20 URLs had been shared and viewed over 1,300 times (i.e., passed from one Internet user to another via social networks such as Facebook, Twitter, YouTube or Digg). The top-ranked URL in 
Table 3. Survey response by age compared to relative Internet usage

\begin{tabular}{|c|c|c|}
\hline Age (y) & $\begin{array}{l}\text { Response Rate (\%) } \\
\qquad(N=27,382)\end{array}$ & $\begin{array}{l}\text { Relative Internet Usage, from Most } \\
\text { Comparable Data Source Available* }\end{array}$ \\
\hline$<18$ & 41.3 & 23.8 (for ages $12-17$ ) \\
\hline 18-29 & 37.8 & 22.3 (for ages 18-29) \\
\hline 30-49 & 13.7 & 21.8 (for ages 30-44) \\
\hline 50-64 & 3.2 & 19.4 (for ages 45-59) \\
\hline $65+$ & 3.9 & 12.7 (for ages $60+$ ) \\
\hline
\end{tabular}

*Source: Zamaria and Fletcher (2008)

Table 4. Distribution of URL postings about vaccine safety by "chat level"

\begin{tabular}{|l|c|c|}
\hline Chat Level & Count & Percentage of Postings \\
\hline High (60 dB) & 55 & 0.32 \\
\hline Medium (40-59 dB) & 475 & 2.73 \\
\hline Low (20-39 dB) & 2,139 & 12.3 \\
\hline None/minimal (0-19 dB) & 14,723 & 84.7 \\
\hline Total & $\mathbf{1 7 , 3 9 2}$ & $\mathbf{1 0 0 . 1}$ \\
\hline
\end{tabular}

URL = uniform resource locator. tion; however, with Canadian Internet usage being $70 \%$ or over for ages $15-64$ (over $80 \%$ for those $15-54$ and $70 \%$ for those 55-64 and rising (Statistics Canada 2009b), our survey accessed at least as wide a net of potential respondents as computer-assisted telephone interviewing. A growing percentage of Canadians do not own a telephone landline or they block telemarketers and polling companies from contacting them. At $15.6 \%$, the relatively low response rate could suggest important differences between those who responded and the majority who did not. For example, the respondents might have had more time available to complete the survey than non-respondents. However, the survey took only 10-60 seconds to complete. The large sample size $(N=$ $27,382)$ reduces concerns about coverage bias. A response rate of $15.6 \%$ is reflective of web surveys generally, response rate being a challenge for all online surveys, even when pre-recruited panels are used (Couper and Miller 2008). We tried to correct for a low response rate by using large, geographically representative, daily, random sampling.

With regard to the findings of our Flu Chat Lab (step B), whose findings are independent and should not be correlated with those in step $A$, the dominant bias

Appendix 1 was shared and then viewed by the person to whom the link was sent over 9,600 times, as of the time of this writing. As of April 6, 2009, the Flu Chat Lab showed that the video "Girl Gets 'Flu' Shot and Now Can Only Walk Backwards" (number 2) had been shared 8,773 times and viewed 2,386,817 times, as indicated by YouTube.

\section{Discussion}

For our daily tracking survey (step A), we attempted to obtain a random sample of Internet users. Based on Tables 1, 2 and 3, we feel we succeeded in approximating geographical representation across Canada, but Tables 2 and 3 reveal that our sample was not representative in terms of sex and age, which may limit the generalizability of our findings. The online nature of our survey skewed the response toward a younger demographic. Women were overrepresented, possibly due to the fact that women are usually the primary caregivers and would thus be more concerned about vaccine safety. One could question whether the universe of Internet users is representative of the popula- is the English-language nature of the postings aggregated. We were limited by query limits imposed by Google Search in terms of the number of search results for each search string. Further, Google Search was the only search engine we used. However, Google Search is by far the most popular search engine in Canada, with the most number of web pages indexed compared with any other search engine in the world.

It is not always possible to interpret the meaning of numbers of mentions of websites since interest can be generated by stories that are amusing, celebrity-focused or popular for other reasons. Nevertheless, we did establish that anti-vaccine sites were generating wide interest among Canadians. There is no direct evidence that viewing anti-vaccine sites led to the perception shared by $41.4 \%$ of Canadians surveyed that the H1N1 vaccine was not safe.

\section{Future Policy Directions}

Prior research has suggested that health-related blogs with clinically relevant and accurate chronic illness information are 

Figure 2. Percentage of Canadians, each day, saying "yes", "no" or "I don't know" to the question,
"Do you think the H1N1 flu vaccine is safe?"

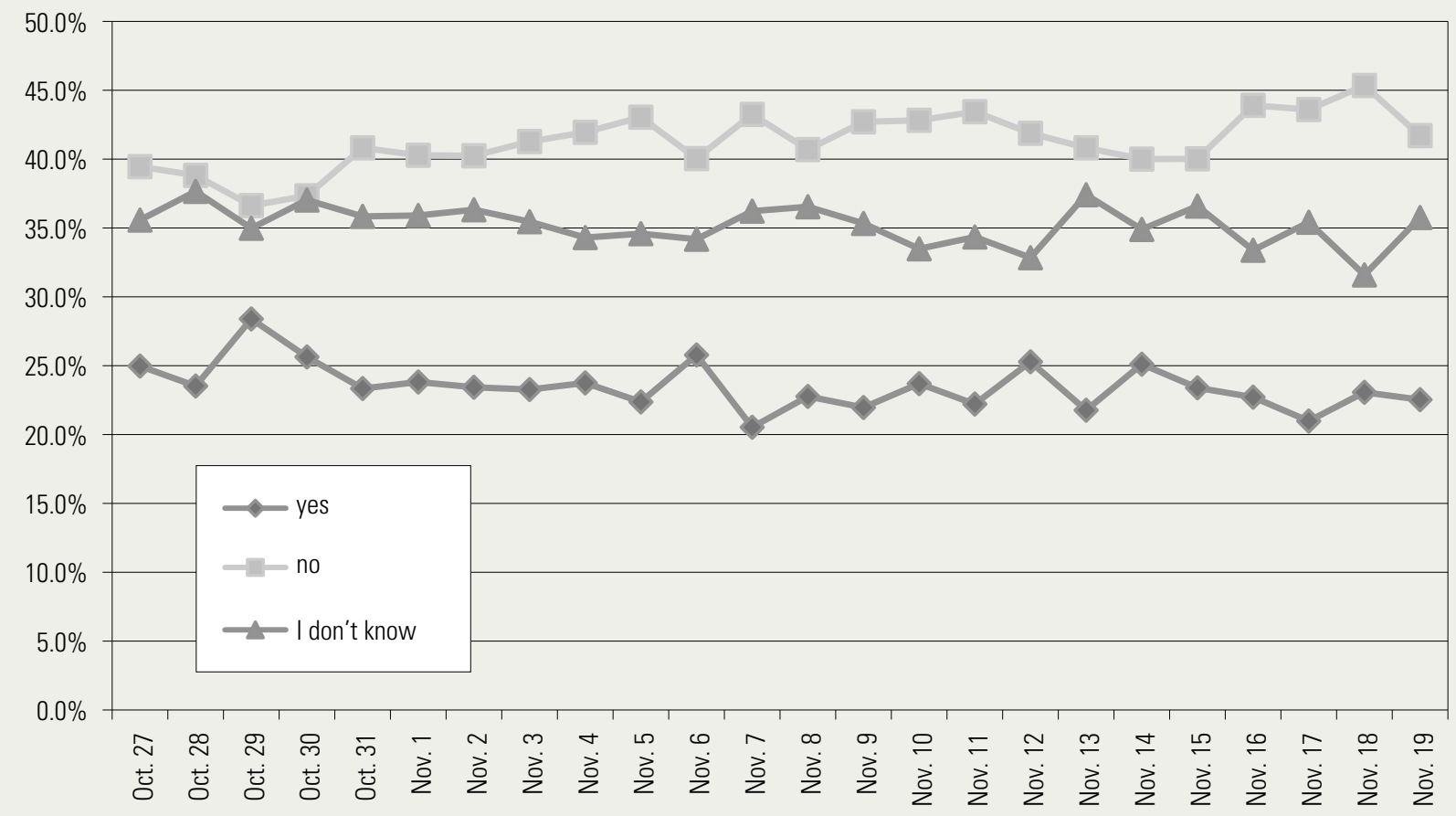

frequently the most viewed and, increasingly, the most trusted by Internet users (Seeman 2009). Nonetheless, our findings in step B show that sustained anti-vaccine sentiment continues to be viewed and shared actively on the web. Our findings from step A show that Canadian Internet users, even after the approval of the $\mathrm{H} 1 \mathrm{~N} 1$ vaccine in Canada, were skeptical, over the course of 24 days, about the vaccine's safety. This suggests that public health authorities may need to use "counter-marketing" strategies.

So-called counter-marketing is a growing social marketing strategy that has been effective in tobacco control (countering the messages of tobacco companies) (Evans and McCormack 2008). An effective counter-marketing strategy can proactively identify and expose misinformation and anecdotal evidence that "tugs at the heart strings" in near real time (Davies et al. 2002).

Our novel approaches to determining public attitudes to healthcare issues using real-time Internet data gathering can be applied more broadly to understand public sentiment, at low cost and with rapidity, on a broad range of policy issues. Step A, for example, has already been used to determine public attitudes among Canadians toward providing social supports (e.g., help with the laundry or other household chores) for chronically ill neighbours (Seeman and Brown in press). Step B can be used to determine the readiness with which people share online information with their peers about taboo subjects such as mental health problems and needs. Highly shared information can help to guide the improved visual design, features and language formatting for online health tools that target subpopulations of interest. Applying both qualitative and quantitative analyses to blogs and exchanges on social networks can potentially tap into the perceptions of large numbers of people with respect to many health issues other than vaccinations (e.g., satisfaction with healthcare services, pathways to care and outcomes and overall experiences of care).

Using tools similar to the ones described here, hospitals, public health agencies, health regions and health ministries can learn about the extent and causes of the public's anti-vaccine sentiments and devise methods to effectively neutralize them. For example, an independent evaluation unit staffed with expert clinical reviewers and social media experts could create a running search string methodology (in both official languages and in other languages reflective of Canada's diverse population) akin to our approach in step B. This approach would identify, in real time, which websites were disseminating popular anti-vaccine-related information. Sites with anti-vaccine sentiment that were growing in intensity could be flagged. These findings could be stored in a secure database accessible by website editors working with public health officials at the national, provincial and local levels, and by web editors working with hospitals and health regions. 
While we have not provided direct evidence that Internet viewing was responsible for the low uptake of the H1N1 vaccine, Betsch et al. (2010) have shown that accessing vaccinecritical websites for five to 10 minutes increases the perception of risk of vaccinating and decreases the perception of risk of not vaccinating. Intentions to vaccinate are diminished by such viewing. Vaccine-critical websites therefore potentially contribute to changes in risk perception, which, in turn, can affect the public's willingness to get vaccinated. Future research should validate the extent to which website information does, in fact, influence perceptions of vaccine safety, public willingness to get vaccinated and other areas of patient safety. Given the amount of resources that companies, charitable organizations and healthcare organizations are currently investing in viral advertising on the web, particularly on social networks, it is likely to have some impact (Seeman 2008); but the exact extent of this impact is hard to assess beyond traditional metrics such as website hits and trends in site usage (e.g., Alexa.com).

There is some literature suggesting that people seek out information that confirms their existing attitudes (Sunstein 2007); therefore, the impact of misinformation about the vaccine might be less than we think. Given the thousands of websites being created every second, competition for public attention online is extremely challenging. Therefore, measures of engagement of the target population, rather than simple website hits, are more valuable to assessing the impact of any online healthcare intervention or information tool. The degree to which the public shares websites (our process in step B), rather than website hits, is one such measure of engagement. Other measures of value include the degree to which potential users of a website can become aware of its existence. Such measures might include the Google "footprint" for the website of interest ("geo-located" to URLs for the target populations); "in-links" to the website; and the extent to which the site is visible on Google when the target populations actively search for related information (e.g., cancer and depressed for people suffering from these overlapping conditions).

\section{Our Approach: Collaborative Counter- Marketing to Address Anti-vaccine Sentiment} What we call a "collaborative counter-marketing model" involves engaging in publicly viewable web discussions with the authors of the anti-vaccine postings. This could be accomplished through an independent evaluation unit's ongoing postings or annotations to the content posted by vaccine dissenters. This approach would show constructive, transparent engagement and provide demonstrable evidence that a counter-marketing strategy is meant to provoke dialogue, not shut down dissent. The public perception of shutting down dissent could, in itself, raise skepticism and anti-vaccine sentiment that could accumulate on blogs and online forums. Under our approach, each region and hospital could engage in meaningful dialogue with locally influential dissenters. Those with disproportionate influence in a particular geographical region could be identified by the evaluation unit using detection methods geo-located to towns, cities and provinces. Local authorities could choose with whom to engage in dialogue in order to achieve maximum impact.

\section{Conclusion}

The web contains much flu-related anti-vaccine sentiment that is potentially dangerous to the perceptions of risk and a willingness to get vaccinated. This challenge, we feel, can potentially be mitigated using real-time web analytics. Current public health communication and education strategies can be complemented by web analytics that identify and track anti-vaccine sentiment on the Internet. A collaborative counter-marketing model can be supported by the type of real-time daily Internet tracking survey described in this article (i.e., step A), making it possible - at a community, city, province, region, or country level - to monitor the success of the collaborative counter-marketing strategy. When, in a future pandemic, scarce public health resources need to be shifted rapidly to regions where anti-vaccination sentiment runs high, a method of collaborative counter-marketing, as described here, can provide the public with accurate risk information, which should help to boost vaccination rates and thereby enhance public safety. $\mathrm{HQ}$

\section{Acknowledgements}

The RIWI Corporation conducted the online survey for step A of this article without compensation, in the public interest. Bob Seeman, a director of RIWI, is the brother of Neil Seeman.

The Health Strategy Innovation Cell is supported by a grant from the Ontario Ministry of Health and Long-Term Care.

\section{References}

Alvarez-Pasquín, A.J., H. Heijbel, J. Yarwood, P. Van Damme and VACSATC partners. 2009. "VACSATC (Vaccine Safety: Attitudes, Training and Communication): Why Such a Project?" Euro Surveillance 14(16): $1-4$

Baeyens, J.P. 2010. "Ensuring the Willingness to Vaccinate and Be Vaccinated." Expert Review of Vaccines 9(3 Suppl.): 11-4.

Betsch, C., F. Renkewitz, T. Betsch and C. Ulshöfer. 2010. "The Influence of Vaccine-Critical Websites on Perceiving Vaccination Risks. Journal of Health Psychology 15(3): 446-55.

comScore Networks, Inc. 2008. Canadians Online. Reston, VA: Author. Retrieved April 6, 2010. <http://ir.comscore.com>.

Couper, M.P. and P.V. Miller. 2008. "Web Survey Methods." Public Opinion Quarterly 72(5): 831-35. Retrieved April 9, 2010. <http:// poq.oxfordjournals.org/cgi/content/full/72/5/831>.

Davies, P., S. Chapman and J. Leask. 2002. "Antivaccination Activists on the World Wide Web." Archives of Disease in Childhood 87(1): 22-5.

Evans, W.D. and L. McCormack. 2008. "Applying Social Marketing in Health Care: Communicating Evidence to Change Consumer Behavior." Medical Decision Making 28(5): 781-92. 
Gollust, S.E. and P.M. Lantz. 2009. "Communicating Population Health: Print News Media Coverage of Type 2 Diabetes." Social Science and Medicine 69(7): 1091-98.

Harris-Decima. 2009. "Concern over H1N1 Jumps Significantly." Ottawa, ON: Author. Retrieved April 9, 2010. <http://www.harrisdecima.com/releases/2009/11/03/365-concern-over-h1n1-jumps-si]>.

Hesse, B.W., D.E. Nelson, G.L. Kreps, R.T. Croyle, N.K. Arora, B.K. Rimer et al. 2005. "Trust and Sources of Health Information: The Impact of the Internet and Its Implications for Health Care Providers: Findings from the First Health Information National Trends Survey." Archives of Internal Medicine 165(22): 2618-24.

Jefferson, T., A. Rivetti, A. Harnden, C. Di Pietrantonj and V. Demicheli. 2008. "Vaccines for Preventing Influenza in Healthy Children. Cochrane Database of Systematic Reviews 2: CD004879. DOI: 10.1002/14651858.CD004879.pub3.

Mareiniss, D.P., J.M. Hirshon and B.C. Thibodeau. 2009. "Disaster Planning: Potential Effects of an Influenza Pandemic on Community Healthcare Resources." American Journal of Disaster Medicine 4(3): 163-71.

Maurer, J., L. Uscher-Pines and K.M. Harris. 2010. "Perceived Seriousness of Seasonal and $\mathrm{A}(\mathrm{H} 1 \mathrm{~N} 1)$ Influenzas, Attitudes toward Vaccination, and Vaccine Uptake among U.S. Adults: Does the Source of Information Matter?" Preventive Medicine 51(2):185-87.

Rizo, C.A, D. Lupea, H. Baybourdy, M. Anderson, T. Closson and A.R. Jadad. 2005. "What Internet Services Would Patients Like from Hospitals during an Epidemic? Lessons from the SARS Outbreak in Toronto." Journal of Medical Internet Research 7(4): e46.

Seale, H., A.E. Heywood, M.L. McLaws, K.F. Ward, C.P. Lowbridge, D. Van et al. 2010. "Why Do I Need It? I Am Not at Risk! Public Perceptions towards the Pandemic (H1N1) 2009 Vaccine." BMC Infectious Disease 19(10): 99.

Seeman, N. 2008. "Web 2.0 and Chronic Illness: New Horizons, New Opportunities." Electronic Healthcare 6(3): 104-10.

Seeman, N. 2009. "Inside the Health Blogosphere: Quality, Governance and the New Innovation Leaders." Electronic Healthcare 7(3): 101-08.

Seeman, N. and A.D. Brown. In press. "We Are Not Bowling Alone.” Queen's Quarterly 117(2).

Seeman, N., G.R. Baker and A.D. Brown. 2008. "Emergency Planning in Ontario's Acute Care Hospitals: A Survey of Board Chairs." Healthcare Policy 3(3): 65-74.

Sunstein, C.R. 2007. Republic.com 2.0. Princeton, NJ: Princeton University Press.

Statistics Canada. 2009a. Population by Year, by Province and Territory. Ottawa, ON: Author. Retrieved April 9, 2010. <http://www40.statcan.gc.ca/101/ cst01/demo02a-eng.htm>.

Statistics Canada. 2009b. Rates of Internet Use, by Age Group, Selected Years (Based on 2007 Data). Ottawa, ON: Author. Retrieved April 9, 2010. <http://www. statcan.gc.ca/pub/11-008-x/2009002/c-g/10910/cg001-eng.htm>.
Wolfe, R.M., L.K. Sharp and M.S. Lipsky. 2002. "Content and Design Attributes of Antivaccination Web Sites. Journal of the American Medical Association 287(24): 3245-48.

Zamaria, C. and F. Fletcher. 2008. Canadian Internet Project (Based on 2007 Data). Retrieved April 9, 2010. Toronto, ON: Author. <http://www.ciponline.ca/en/docs/2008/CIP07\%20CANADA\%20 ONLINE-HIGHLIGHTS.pdf>.

\begin{abstract}
About the Authors
Neil Seeman, JD, MPH, is a member of the Health Strategy Innovation Cell, Massey College, at the University of Toronto, and the Department of Health Services Management, Ryerson University, in Toronto, Ontario. You can contact him by phone at $416-205-9984$, by fax at $416-352-5071$ or by email at neil. seeman@utoronto.ca.
\end{abstract}

Alton Ing, BaSc, MaSc, is a member of the Health Strategy Innovation Cell, Massey College, at the University of Toronto.

Carlos Rizo, MD, is a member of the Health Strategy Innovation Cell, Massey College, at the University of Toronto.

\section{Patient and staff safety are inseparably linked}

At Vancouver Coastal Health, we believe that safe and healthy staff ensure safe patient care.

We are committed to active involvement in targeting improvements to the health and well being of employees, the healthiness of the workplace and the sustainability of the health care system. We encourage a safety culture of open communication that invites participation and knowledge exchange. And we extend our health and safety efforts beyond the workplace by engaging with our community partners and educational institutions, resulting in benefits that contribute to healthy workplaces and to patient safety.

Vancouver Coastal Health. Delivering primary through quaternary care and services to residents of Metro Vancouver and across British Columbia.

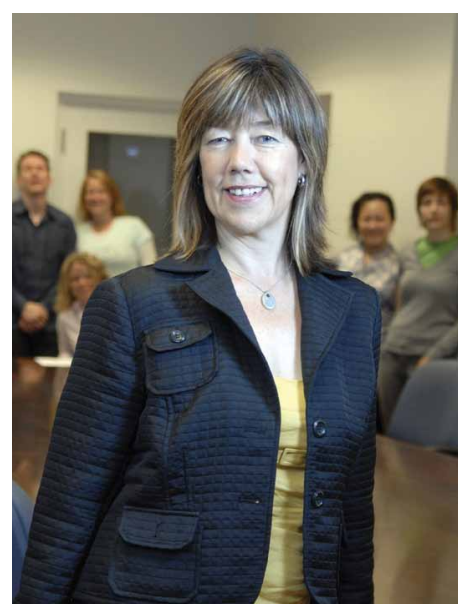

Mary M., Practice Initiatives Lead Vancouver Coastal Health
Care. Teaching. Research.

$$
\text { www.vch.ca }
$$

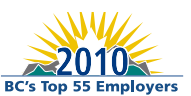




\section{Assessing and Responding in Real Time to Online Anti-vaccine Sentiment during a Flu Pandemic}

Neil Seeman, Alton Ing and Carlos Rizo

Appendix 1. Most discussed 20 search results about the H1N1's vaccine clinical safety (as of April 6, 2010)

\begin{tabular}{|c|c|c|c|}
\hline $\begin{array}{l}\text { Rank out of Top } 20 \\
\text { (N = 17,392) }\end{array}$ & $\begin{array}{l}\text { 'Chat Level' } \\
\text { (dB) }\end{array}$ & Web Posting Describing URL Content & Source Site and Context \\
\hline 1 & 80.0 & $\begin{array}{l}\text { "I was exposed to } 2 \text { people on } 2 \text { diff occasions, both } \\
\text { had swine flu and im fine. all u need is vit } C \text { and fish } \\
\text { oil. and oh by the way, i work in a convenience store } \\
\text { and am exposed to hundreds of people per day and } \\
\text { their filthy money." }\end{array}$ & $\begin{array}{l}\text { http://www.youtube.com } \\
\text { [Comment by bobthe24 on YouTube] }\end{array}$ \\
\hline 2 & 79 & $\begin{array}{l}\text { "Girl gets 'Flu' Shot \& Now Can Only Walk Backwards } \\
\text {.. Experts claim serious side effects of flu shots } \\
\text { amount to about one in a million - well this is what } \\
\text { that one in a million looks like. This has freaked me } \\
\text { out enough to bypass flu shots in the future." }\end{array}$ & $\begin{array}{l}\text { http://www.youtube.com } \\
\text { [Video posted by freshtildeathonline on } \\
\text { YouTube] }\end{array}$ \\
\hline 3 & 77 & $\begin{array}{l}\text { "The current strain, } A(\mathrm{H} 1 \mathrm{~N} 1) \text {, is a new variation of an } \\
\text { H1N1 virus - which causes seasonal flu outbreaks in } \\
\text { humans - that also contains genetic material of bird } \\
\text { and pig versions of the flu. Symptoms include: Fever } \\
\text { of more than 100; Coughing; Runny nose and/or sore } \\
\text { throat; Joint aches; Severe headache; Vomiting and/ } \\
\text { or diarrhea; Lethargy; Lack of appetite..." }\end{array}$ & $\begin{array}{l}\text { http://articles.mercola.com } \\
\text { [Article titled "Critical Alert: The Swine Flu } \\
\text { Pandemic - Fact or Fiction?"] }\end{array}$ \\
\hline 4 & 76 & $\begin{array}{l}\text { "Now some flu experts are challenging the medical } \\
\text { orthodoxy and arguing that for those most in need of } \\
\text { protection, flu shots and antiviral drugs may provide } \\
\text { little to none ... while vaccines for, say, whooping } \\
\text { cough and polio clearly and dramatically reduced } \\
\text { death rates from those diseases, the impact of flu } \\
\text { vaccine has been harder to determine." }\end{array}$ & $\begin{array}{l}\text { http://theatlantic.com } \\
\text { [Article titled "Does the Vaccine Matter? - The } \\
\text { Atlantic (November 2009)] }\end{array}$ \\
\hline 5 & 73 & $\begin{array}{l}\text { "It was previously revealed that some batches of } \\
\text { the vaccine will contain mercury, a toxin linked with } \\
\text { autism and neurological disorders. The vaccine will } \\
\text { also contain the dangerous ingredient squalene, } \\
\text { which has been directly linked with cases of Gulf War } \\
\text { Syndrome and a host of other debilitating diseases." }\end{array}$ & $\begin{array}{l}\text { http://www.prisonplanet.com and aggregated } \\
\text { at http://jimcorr.com } \\
\text { [Article titled "CDC Warns Neurologists to } \\
\text { Watch for Nerve Disease following Swine Flu } \\
\text { Shots"] }\end{array}$ \\
\hline 6 & 71 & $\begin{array}{l}\text { "Pregnant mothers are more [at] risk for H1N1 and } \\
\text { are more likely to be hospitalized." }\end{array}$ & $\begin{array}{l}\text { http://informationisbeautiful.net } \\
\text { [Article titled "Is the H1N1 Swine Flu Vaccine } \\
\text { Safe? What if I'm Pregnant?"] }\end{array}$ \\
\hline
\end{tabular}




\begin{tabular}{|c|c|c|c|}
\hline $\begin{array}{l}\text { Rank out of Top } 20 \\
\text { (N =17,392) }\end{array}$ & $\begin{array}{l}\text { 'Chat Level' } \\
\text { (dB) }\end{array}$ & Web Posting Describing URL Content & Source Site and Context \\
\hline 7 & 70 & $\begin{array}{l}\text { "Flu Vaccine DOUBLES Risk of Getting H1N1 ... It } \\
\text { is also important to view this in the face of the new } \\
\text { unpublished Canadian study of } 12 \text { million people } \\
\text { that found getting the seasonal flu vaccine, as } \\
\text { recommended by the CDC and NIH, doubles one's } \\
\text { risk of developing the H1N1 infection. It would also } \\
\text { make the infection much more serious. So much for } \\
\text { expert advice from the government." }\end{array}$ & $\begin{array}{l}\text { http://articles.mercola.com } \\
\text { [Article titled "Swine Flu - One of the Most } \\
\text { Massive Cover-ups in American History"] }\end{array}$ \\
\hline 8 & 70 & $\begin{array}{l}\text { "It is safe for children and pregnant women to } \\
\text { receive a flu vaccine that contains thimerosal." }\end{array}$ & $\begin{array}{l}\text { http://flu.gov } \\
\text { [Assistant Surgeon General Dr. Anne Schuchat } \\
\text { dispels myths about the H1N1 flu virus on The } \\
\text { Doctors] }\end{array}$ \\
\hline 9 & 68 & $\begin{array}{l}\text { "Pregnant women, children, and those whose } \\
\text { immune system are already compromised are also } \\
\text { at greater risk to suffer severe side effects from the } \\
\text { vaccine, as the adjuvants in the vaccine are designed } \\
\text { to reduce your immune function." }\end{array}$ & $\begin{array}{l}\text { http://articles.mercola.com } \\
\text { [Comment by “Dr. Mercola" called "Warning: } \\
\text { Swine Flu Shot Linked to Killer Nerve Disease"] }\end{array}$ \\
\hline 10 & 68 & $\begin{array}{l}\text { "Vaccinations do not optimize immune function and } \\
\text { there is way too little information about what else } \\
\text { they do in the human body that may contribute to } \\
\text { poor health. My main point is that there are ways } \\
\text { to prevent illness and maintain health that are so } \\
\text { much more natural, easier, less expensive and more } \\
\text { effective than routine use of multiple vaccines in } \\
\text { childhood and throughout life." }\end{array}$ & $\begin{array}{l}\text { http://articles.mercola.com } \\
\text { [Comment by “Dr. Mercola" called "Alert: } \\
\text { Special Swine Flu Update"] }\end{array}$ \\
\hline 11 & 68 & $\begin{array}{l}\text { "Getting vaccinated is by far the most effective thing } \\
\text { you can do to protect yourself and your family from } \\
\text { swine flu." }\end{array}$ & $\begin{array}{l}\text { http://www.newscientist.com } \\
\text { [Article titled "Swine Flu: Eight Myths That } \\
\text { Could Endanger Your Life"] }\end{array}$ \\
\hline 12 & 66 & $\begin{array}{l}\text { "Flu should never be dismissed as 'just the flu.' It's } \\
\text { a serious disease, and while most cases are mild, } \\
\text { some can be deadly. So far this flu season, most flu } \\
\text { activity has been caused by the } 2009 \text { H1N1 virus, } \\
\text { which was first identified in April } 2009 \text { and caused } \\
\text { the first flu pandemic in } 40 \text { years." }\end{array}$ & $\begin{array}{l}\text { http://cdc.gov } \\
\text { [CDC's Questions and Answers: "Vaccine } \\
\text { against } 2009 \text { H1N1 Influenza Virus"] }\end{array}$ \\
\hline 13 & 66 & $\begin{array}{l}\text { "Your immune system recognizes squalene as an oil } \\
\text { molecule native to your body. It is found throughout } \\
\text { your nervous system and brain. In fact, you can } \\
\text { consume squalene in olive oil and not only will your } \\
\text { immune system recognize it, you will also reap the } \\
\text { benefits of its antioxidant properties. The difference } \\
\text { between 'good' and 'bad' squalene is the route by } \\
\text { which it enters your body. Injection is an abnormal } \\
\text { route of entry which incites your immune system } \\
\text { to attack all the squalene in your body, not just the } \\
\text { vaccine adjuvant. Your immune system will attempt } \\
\text { to destroy the molecule wherever it finds it, including } \\
\text { in places where it occurs naturally, and where it is } \\
\text { vital to the health of your nervous system. }\end{array}$ & $\begin{array}{l}\text { http://articles.mercola.com } \\
\text { [Comment by “Dr. Mercola" called "Squalene: } \\
\text { The Swine Flu Vaccine's Dirty Little Secret } \\
\text { Exposed"] }\end{array}$ \\
\hline
\end{tabular}




\begin{tabular}{|c|c|c|c|}
\hline $\begin{array}{l}\text { Rank out of Top } 20 \\
(\mathrm{~N}=17,392)\end{array}$ & $\begin{array}{l}\text { 'Chat Level' } \\
\text { (dB) }\end{array}$ & Web Posting Describing URL Content & Source Site and Context \\
\hline 14 & 65 & $\begin{array}{l}\text { "Study after study, and master studies that } \\
\text { compile the results from several studies to get a } \\
\text { more objective result, keep coming to the same } \\
\text { conclusion: Flu vaccines DO NOT WORK, and in } \\
\text { many cases do more harm than good." }\end{array}$ & $\begin{array}{l}\text { http://articles.mercola.com } \\
\text { [Comment by “Dr. Mercola" called "Flu Vaccine } \\
\text { Exposed"] }\end{array}$ \\
\hline 15 & 65 & $\begin{array}{l}\text { "The risks of these, and the current fast-tracked } \\
\text { swine flu vaccine, are truly unknown at this time. } \\
\text { There is NO Incentive for the CDC or Vaccine } \\
\text { Manufacturers to Care About Safety." }\end{array}$ & $\begin{array}{l}\text { http://articles.mercola.com } \\
\text { [Comment by “Dr. Mercola" called "CBS Reveals } \\
\text { That Swine Flu Cases Seriously Overestimated"] }\end{array}$ \\
\hline 16 & 65 & $\begin{array}{l}\text { "None of the vaccines have been subjected to } \\
\text { real-world testing for any meaningful duration. } \\
\text { The 'safety' of these vaccines is nothing more than } \\
\text { wishful thinking." }\end{array}$ & $\begin{array}{l}\text { http://www.naturalnews.com } \\
\text { [Article titled "Ten Swine Flu Lies Told by the } \\
\text { Mainstream Media"] }\end{array}$ \\
\hline 17 & 64 & $\begin{array}{l}\text { "Adjuvants are used in vaccines in order to create } \\
\text { a sufficiently strong immunological response. } \\
\text { Adjuvants augment your immunological response. } \\
\text { But there is clear evidence that adjuvants, like } \\
\text { aluminum and squalene impair your immune system. }\end{array}$ & $\begin{array}{l}\text { http://articles.mercola.com } \\
\text { [Comment by “Dr. Mercola" called "Expert } \\
\text { Pediatrician Exposes Vaccine Myths"] }\end{array}$ \\
\hline 18 & 63 & $\begin{array}{l}\text { "If you have any of the conditions that put you at } \\
\text { increased risk of severe H1N1 swine flu - pregnancy, } \\
\text { asthma, lung disease, diabetes, heart disease, } \\
\text { neurologic disease, immune suppression, or other } \\
\text { chronic conditions - it may be riskier for you to get } \\
\text { the flu than for other people." }\end{array}$ & $\begin{array}{l}\text { http://www.webmd.com } \\
\text { [Article titled "Swine Flu FA0"] }\end{array}$ \\
\hline 19 & 63 & $\begin{array}{l}\text { "There is absolutely no scientific evidence } \\
\text { demonstrating that the swine flu vaccine offers real- } \\
\text { world protection against the circulating H1N1 virus. } \\
\text { While there is evidence showing that it produces } \\
\text { antibodies, as people who have studied vaccine } \\
\text { effectiveness already know, the mere existence of } \\
\text { vaccine-induced antibodies doesn't directly translate } \\
\text { into functional, real-world immunity! Vaccines are } \\
\text { often, in effect, fabricated immunity that often don't } \\
\text { provide practical immune defense in the real world." }\end{array}$ & $\begin{array}{l}\text { http://www.naturalnews.com } \\
\text { [Article titled "Vaccine Revolt! Swine Flu } \\
\text { Vaccine Support Crumbles"] }\end{array}$ \\
\hline 20 & 63 & $\begin{array}{l}\text { "The H1N1 vaccine is expected to be as safe as } \\
\text { seasonal flu vaccine. H1N1 vaccine is made in the } \\
\text { same way and in the same licensed facilities used } \\
\text { to make seasonal flu vaccines. People with a severe } \\
\text { allergy to chicken eggs or to another substance in } \\
\text { the vaccine, or who have had a serious reaction to } \\
\text { flu vaccine should not be vaccinated." }\end{array}$ & $\begin{array}{l}\text { http://www.azdhs.gov } \\
\text { ["Fact sheet" from the Arizona government's } \\
\text { news release on H1N1] }\end{array}$ \\
\hline
\end{tabular}


ACCREDITATION CANADA

AGRÉMENT CANADA

Driving Quality Health Services

Force motrice de la qualité des

services de santé

\section{Working with you to achieve your quality improvement goals}

For over 50 years, Accreditation Canada has been helping health and social services organizations strive for excellence through accreditation.

Accreditation demonstrates your commitment to patient safety and quality by assessing your organization's programs and services against the highest standards in health care.

Accreditation Canada's adaptable and evidence-based programs can help your organization take the next step on the quality improvement journey.

Call today to learn more.

E-mail LearnMore@accreditation.ca

Visit www.accreditation.ca

Call 1-800-814-7769 ext. 299

Proud to be accredited by the International Society for Quality in Health Care (ISQua) 